\title{
Pengaruh Person Organization Fit terhadap Employee Outcomes dengan Job Satisfaction sebagai Variabel Intervening
}

\section{The Effect of Person Organization Fit on Employee Outcomes with Job Satisfaction as Intervening Variable}

\author{
Dominicus Wahyu Pradana ${ }^{*}$, Daniel Tulasi ${ }^{1}$ \\ 1)Prodi Manajemen, Fakultas Bisnis, Universitas Katolik Widya Mandala Surabaya, Indonesia \\ *Coresponding Email: wahyupradana@ukwms.ac.id
}

\begin{abstract}
Abstrak
Penelitian ini bertujuan mengkaji faktor yang mempengaruhi employee outcomes, yang menggunakan dimensidimensi person organization fit yaitu variabel values congruence, personality congruence, work environment congruence, dengan job satisfaction sebagai variabel intervening. Penelitian ini termasuk kategori penelitian konklusif yang mencari hubungan kausal antara person organization fit dan employee outcomes melalui job satisfaction. Terdapat 7 hipotesis yang diajukan untuk membuktikan pengaruh langsung maupun tidak langsung antara variabel independen terhadap variabel dependen melalui variabel intervening. Pengumpulan data dilakukan dengan metode survey dengan alat pengumpulan data berupa kuesioner yang dibagikan kepada para pegawai administrasi pada Perguruan Tinggi Swasta di Surabaya sebanyak 104 responden. Setelah data terkumpul, kemudian diolah dan dianalisis dengan menggunakan analisis SEM-PLS 3.0. Bendasarkan hasil analisis dan pembahasan tentang hubungan antara faktor person organization fit dan employee outcomes (EO) yang pada penelitian ini diproksikan dengan komitmen organisasional (organizational commitment), maka kesimpulan integratif dari penelitian ini adalah person organization fit (PO fit) dapat memengaruhi employee outcome baik secara langsung maupun melalui job satisfaction sebagai variabel intervening.

Kata Kunci: Person Organization Fit, Job Satisfaction, Employee Outcomes.
\end{abstract}

\begin{abstract}
This study examines the factors that influence employee outcomes, using the dimensions of person organization fit, namely the values congruence, personality congruence, work environment congruence, and job satisfaction as an intervening variable. This research belongs to the category of conclusive research that seeks a causal relationship between person organization fit and employee outcomes through job satisfaction. There are 7 hypotheses proposed to prove the direct or indirect effect between the independent and dependent variable through the intervening variable. Data was collected using a survey method with data collection tools in questionnaires distributed to administrative employees at private universities in Surabaya as many as 104 respondents. After the data is collected, then it is processed and analyzed using SEM-PLS 3.0. Based on the results of the analysis and discussion of the relationship between the factor of person-organization fit and employee outcomes (EO) which in this study is proxied by organizational commitment (organizational commitment), the integrative conclusion of this study is that person organization fit (PO fit) can affect employees outcome either directly or through job satisfaction as an intervening variable
\end{abstract}

Keywords: Person Organization Fit, Job Satisfaction, Employee Outcomes.

How to Cite: Pradana, D.W. \& Tulasi, D. (2021). Pengaruh Person Organization Fit Terhadap Employee Outcomes Dengan Job Satisfaction Sebagai Variabel Intervening. JKBM (Jurnal Konsep Bisnis dan Manajemen). 8 (1): 70-80 


\section{PENDAHULUAN}

Organisasi pada era baru ini berada pada iklim persaingan yang kompetitif, sebagai dampak dari globalisasi maupun disrupsi teknologi yang begitu cepat. Organisasi harus dapat mengidentifikasi keunggulan dan ancaman yang dimiliki. Aset paling berharga yang dimiliki oleh perusahaan saat ini bukan hanya terletak pada aktivitasnya, proses produksinya, ataupun pada peralatan yang digunakan, akan tetapi pada sumber daya manusianya sebagai penggerak yang menyusun organisasi (Perera, 2014). Karyawan sebagai aset sudah seharusnya diseleksi, diperlakukan, dan dikelola dengan baik demi keberhasilan organisasi (Chen et al., 2016; Lau et al., 2017).

Organisasi percaya pada aspek person organization fit untuk membedakan antara kandidat karyawan yang qualified dan yang tidak, dengan mengidentifikasi kesesuaian antara nilai-nilai individu dan organisasi atau personality dengan organisasi (Uysal-Irak, 2017). Organisasi perlu selalu melihat bagaimana perilaku karyawan sejak dalam proses seleksi sampai ketika karyawan itu melaksanakan tugasnya.

Person organization fit adalah sebuah kerangka umum yang mengkombinasikan antara individu (karyawan), situasi, dan variabel proses ketika mempelajari perilaku karyawan dan harus dibuktikan bagaimana pengaruhnya pada fungsi dan perubahan organisasi (Perera, 2014). Studi terdahulu menyebutkan bahwa kesesuaian antara nilai pribadi dan organisasi akan berdampak positif bagi outcomes atau hasil yang dicapai karyawan. Outcomes tersebut antara lain dapat terlihat dalam tingkat kepuasan kerja, komitmen organisasi, maupun kinerja karyawan secara keseluruhan.
Person organization fit (PO fit) juga dihubungkan secara positif dengan komitmen organisasional (Rumangkit \& Maryati, 2017). Komitmen organisasional didefinisikan sebagai tingkat kekerapan identifikasi dan keterikatan individu terhadap organisasi yang dimasukinya, di mana karakteristik komitmen organisasional antara lain adalah loyalitas seseorang terhadap organisasi, kemauan untuk mempergunakan usaha atas nama organisasi, kesesuaian antara tujuan seseorang dengan tujuan organisasi (Astakhova, 2016; Rumangkit \& Maryati, 2017).

Perera (2014) dalam penelitiannya membuktikan bahwa terdapat hubungan yang positif dan signifikan antara employee organization congruence dengan peningkatan kinerja. Artinya bahwa ketika terdapat kesesuaian antara nilai-nilai yang diyakini pribadi dan nilai-nilai perusahaan, maka kepuasan kerja juga akan meningkat dan pada akhirnya berdampak pada outcome atau kinerja. Demikian pula studi yang dilakukan Uysal-Irak (2017) yang menyatakan bahwa value congruence berkorelasi terhadap kepuasan kerja.

Employee outcomes dalam pengertian luas diartikan sebagai capaian dari karyawan dalam organisasi. Beberapa hasil penelitian tentang employee outcomes menyatakan bahwa employee outcomes adalah sebuah variabel dependen akhir yang diindikasikan dengan tiga variabel terukur yaitu job performance (Perera, 2014), keinginan untuk bertahan dan organizational citizienship behavior (Magdalena, 2014).

Kepuasan kerja membahas tentang sikap karyawan terhadap pekerjaannya. Kepuasan kerja diartikan sebagai keadaan emosi yang senang atau emosi positif yang berasal dari penilaian pe- 
Pradana, D.W. \& Tulasi, D. (2021). Pengaruh Person Organization Fit Terhadap Employee Outcomes Dengan Job ...

kerjaan atau pengalaman kerja seseorang (Luthans, 2015). Definisi tersebut mencakup aspek sikap kognitif (reaksi), afektif, dan evaluatif karyawan atas pekerjaannya. Jadi kepuasan kerja merupakan hasil dari persepsi karyawan mengenai seberapa baik pekerjaannya memberikan hal yang dinilai penting. Terdapat sepuluh aspek utama dalam organisasi yang memberikan respon terhadap kepuasan kerja, sebagaimana diungkapkan Sutrisno (2009) dalam Nasution, (2017) yang menjelaskan beberapa faktor yang mempengaruhi kepuasan kerja: 1) Kesempatan untuk maju; 2) Keadaan yang aman sangat mempengaruhi perasaan karyawan selama kerja; 3) Ketiga gaji, gaji lebih banyak yang menyebabkan ketidakpuasan; 4) Keempat perusahaan dan manajemen, perusahaan dan manajemen yang baik adalah yang mampu memberikan situasi dan kondisi kerja yang stabil; 5) Pengawasan sekaligus atasannya, supervisi yang buruk dapat berakibat absensi dan turnover; 6) Faktor Interistik dari pekerjaan; 7) Kondisi kerja; 8) Aspek sosial dalam pekerjaan; 9) Komunikasi; 10) Fasilitas- fasilitas.

Banyak perusahaan swasta di Indonesia yang mengalami masalah ketidaksesuaian harapan antara pemilik atau pemimpin perusahaan dengan karyawan. Data yang dirilis oleh The Society for Human Resources Management (SHRM), (2020) melaporkan bahwa mengganti karyawan membutuhkan banyak biaya. Biaya pergantian langsung mencapai 50\%-60\% dari gaji tahunan karyawan. Sedangkan total biaya pergantian karyawan dapat mencapai 90\%-200\% dari gaji tahunan. Fenomena ini tentu cukup mengganggu keberlangsungan operasional perusahaan. Perusahaan harus peka terhadap permasalahan ini apabila ingin tetap mempertahankan karyawannya. Karyawan sebagai aset seharusnya diseleksi, diperlakukan, dan dikelola dengan baik demi keberhasilan organisasi. Outcome yang sesuai target, komitmen karyawan yang terbangun, serta kepuasan kerja yang tinggi diharapkan akan tercipta ketika karyawan maupun pemilik perusahaan menyadari akar masalah yang terjadi.

Penelitian ini merupakan penelitian lanjutan untuk menguji kembali faktor person organization fit dalam menunjang pencapaian hasil yang maksimal dari para karyawan. Hasil penelitian Perera (2014) yang menunjukkan bahwa personality congruence berpengaruh positif dan signifikan terhadap employee outcome membuka peluang bagi penelitian ini untuk menguji kembali hubungan kedua variabel dengan objek penelitian di Indonesia. Berdasarkan tinjauan penelitian yang pernah dilakukan serta melihat fenomena yang ada, penelitian ini bertujuan mengkaji pengaruh antara person organization fit terhadap outcome karyawan yang dimediasi oleh faktor kepuasan kerja (job satisfaction).

Individu menggunakan nilai-nilai untuk membuat pilihan-pilihan, termasuk pilihan terkait partisipasinya dalam organisasi. Lalu organisasi menggunakan nilai-nilai untuk mengembangkan budaya yang menjadi acuan keyakinan dan perilaku karyawan yang bisa diterima organisasi. Persamaan antara nilai-nilai individual dan sistem nilai organisasi merupakan salah satu ukuran dari PO fit (Uysal-Irak, 2017). Maka hipotesis yang diajukan dalam penelitian ini:

- H1: Values congruence berpengaruh positif terhadap employee outcome. 
Personality congruence adalah sebuah personality prototype dari seorang anggota organisasi yang sukses ideal jika digunakan sebagai standar untuk menentukan personality fit (Kristof, 1996). Beberapa studi empiris menemukan bahwa antara personality type dan the modal personality type memiliki hubungan yang signifikan dengan job satisfaction (Uysal-Irak, 2017). Maka hipotesis yang diajukan:

- H2: Personality congruence berpengaruh positif terhadap employee outcome

Pengaruh Work Environment Congruence terhadap Employee Outcome dapat dilihat dari pernyataan Naz et al., (2020) work environment congruence dapat dioperasionalkan pada suatu keadaan kesesuaian antara karakteristik individual dan lingkungan yang dikenal sebagai needspress associations atau needs-supplies fit (Edwards, 1991; dalam Kristof, 1996; Perera, 2014). Press atau supplies menunjukkan determinan perilaku, khususnya bagaimana lingkungan kerja membantu atau merintangi pemenuhan kebutuhan-kebutuhan karyawan. Oleh karena itu ada hubungan positif signifikan antara needs-supplies fit dan employee outcome. Maka hipotesis yang diajukan:

- H3: Work environment congruence berpengaruh positif terhadap employee outcome

Hubungan antara kepuasan kerja dan employee outcome sudah banyak dibahas oleh banyak peneliti (Allen \& Meyer, 1990) terutama keterkaitan antara kepuasan kerja dan organizational commitment (sebagai salah satu produk dari employee outcome). Hasil penelitian para periset berbeda, setidaknya terbagi atas dua kelompok. Job satisfaction dapat memprediksi or- ganizational commitment (Ćulibrk et al., 2018; Valaei \& Rezaei, 2016), maka hipotesis yang diajukan:

- H4: Kepuasan kerja berpengaruh positif terhadap employee outcome

Variabel PO fit dan employee outcomes (EO) pada penelitian ini diproksikan dengan komitmen organisasional (organizational commitment) menunjukkan bahwa ada hubungan langsung dan tidak langsung antara $P O$ fit dan komitmen organisasional (Dunaetz et al., 2020). Hubungan tidak langsung antara PO fit dan komitmen organisasional salah satunya melalui kepuasan kerja (job satisfaction). Akan tetapi menurut Arkoubi, K.A et al., (2011) dan Luthans, (2015). hubungan kepuasan kerja dan komitmen organisasional masih menimbulkan kontroversi. Beberapa peneliti menemukan bahwa hubungan antara kepuasan kerja dan komitmen organisasional merupakan hubungan korelasional dan bukan hubungan kausal. Akan tetapi kebanyakan kajian teoritis dan riset empiris menunjukkan bahwa kepuasan kerja merupakan anteseden terhadap komitmen organisasional. EOC model misalnya, menjelaskan bahwa kepuasan kerja merupakan predictor of outcome seperti komitmen organisasional, prestasi kerja, produktivitas kerja, keinginan untuk bertahan di perusahaan, keinginan untuk keluar dari perusahaan, dan tingkat absensi (Arkoubi, K.A. et al., 2011). Dengan demikian, kepuasan kerja dapat menjadi anteseden dan mediator bagi employee outcome. Maka hipotesis yang diajukan sebagai berikut.

- H5: Kepuasan kerja memediasi pengaruh value congruence terhadap employee outcome 
Pradana, D.W. \& Tulasi, D. (2021). Pengaruh Person Organization Fit Terhadap Employee Outcomes Dengan Job ...

- H6: Kepuasan kerja memediasi pengaruh personality congruence terhadap employee outcome

- H7: Kepuasan kerja memediasi pengaruh work environment congruence terhadap employee outcome
Model penelitian ini dibangun berdasarkan kerangka teoritis yang dijelaskan dalam hubungan antar variabel-variabel penelitian dan ditunjukkan pada gambar berikut ini.

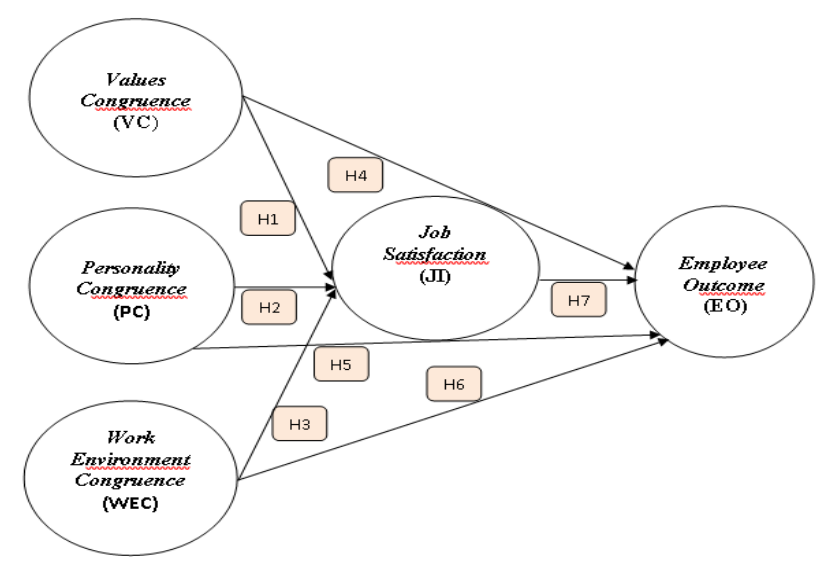

Gambar 1. Kerangka Penelitian

\section{METODE PENELITIAN}

Variabel yang digunakan pada penelitian ini terdiri dari variabel dependen yaitu employee outcome, variabel independen yaitu person organization fit dan variabel intervening yaitu job satisfaction. Populasi dalam penelitian ini adalah seluruh karyawan bagian administrasi atau tenaga pelaksana yang bekerja pada Perguruan Tinggi Swasta di Surabaya.

Penelitian ini meng-gunakan metode nonprobability sampling, khususnya purposive sampling. Jumlah sampel seba-nyak 104 responden. Metode yang digunakan untuk mengumpulkan data penelitian adalah metode survey dengan kuesioner.

Nilai suatu konstruk dikatakan reliabel jika nilai composite reliability $>0,70$. Uji validitas dilakukan dengan menggunakan evaluasi measurement model (outer). Convergent validity dari measurement model dengan indikator refleksif dapat dilihat dari korelasi antara masing-masing skor indikator dengan skor konstruknya (Hair et al., 2016).

Analisis data dilakukan dengan menggunakan SmartPLS 3.0, dengan tiga kriteria untuk menilai outer model yaitu convergent validity, discriminant validity dan composite reliability. Ukuran refleksif individual dikatakan tinggi jika berkorelasi lebih dari 0,70. Pengujian inner model atau model struktural dilakukan untuk melihat hubungan antara variabel, nilai signifikansi dan $R$ square dari model penelitian. Batas untuk menolak dan menerima hipotesis yang diajukan adalah $\pm 1,96$. Apabila nilai t berada pada rentang nilai 1,96 dan 1,96 maka hipotesis akan ditolak atau dengan kata lain menerima hipotesis nol (H0).

\section{HASIL DAN PEMBAHASAN}

Untuk mendapatkan gambaran mengenai profil responden (karyawan), berikut deskripsi 
tentang karakteristik karyawan berdasarkan je- nis kelamin, usia, dan pendidikan terakhir.

Tabel 1. Karakteristik Responden

\begin{tabular}{ccc}
\hline Jenis Kelamin & Jumlah & Prosentase \\
\hline Laki & 73 & $70 \%$ \\
\hline Wanita & 31 & $30 \%$ \\
\hline Jumlah & $\mathbf{1 0 4}$ & $\mathbf{1 0 0 \%}$ \\
\hline Usia & Jumlah & Prosentase \\
\hline $18-20$ & 22 & $21 \%$ \\
\hline $21-30$ & 32 & $31 \%$ \\
\hline $31-40$ & 23 & $22 \%$ \\
\hline $41-50$ & 17 & $16 \%$ \\
\hline Usia & Jumlah & Prosentase \\
\hline$>50$ & 10 & $10 \%$ \\
\hline Jumlah & $\mathbf{1 0 4}$ & $\mathbf{1 0 0 \%}$ \\
\hline Pendidikan & Jumlah & Prosentase \\
\hline SMA/ Sederajat & 35 & $34 \%$ \\
\hline Diploma/Sederajat & 24 & $23 \%$ \\
\hline Sarjana & 45 & $43 \%$ \\
\hline Jumlah & $\mathbf{1 0 4}$ & $\mathbf{1 0 0 \%}$ \\
\hline Sumber Data Diolah & 2020 &
\end{tabular}

Sumber Data Diolah, 2020

Pengujian validitas konstruk pada peneli- nilai outer loading $>0,7$ dan AVE $>0,5$. Berikut tian ini didasarkan parameter skor loading atau hasil pengujian validitas konstruk penelitian:

Tabel 2 Rangkuman Factor Loading Konstruk Penelitian

\begin{tabular}{|c|c|c|c|}
\hline Variabel & Simbol & Indikator & Factor Loading \\
\hline \multirow{3}{*}{ Employee Outcome } & \multirow{3}{*}{ EO } & E01 & 0,705 \\
\hline & & EO2 & 0,730 \\
\hline & & E06 & 0,808 \\
\hline \multirow{3}{*}{ Job Satisfaction } & \multirow{3}{*}{ JS } & JS1 & 0,725 \\
\hline & & JS5 & 0,771 \\
\hline & & JS6 & 0,871 \\
\hline \multirow{2}{*}{ Personality Congruence } & \multirow{2}{*}{ PC } & PC1 & 0,896 \\
\hline & & PC3 & 0,777 \\
\hline \multirow{2}{*}{ Values Congruence } & \multirow{2}{*}{$\mathrm{VC}$} & VC2 & 0,887 \\
\hline & & VC3 & 0,921 \\
\hline \multirow{2}{*}{ Work Environment Congruence } & \multirow{2}{*}{ WEC } & WEC3 & 0,855 \\
\hline & & WEC4 & 0,799 \\
\hline
\end{tabular}

Sumber: data diolah, 2020

Dapat disimpulkan bahwa semua konstruk lebih besar dari pada nilai korelasi antar variabel laten telah memenuhi validitas diskriminan kare- laten. Hasil pengujian realibilitas variabel-variana nilai akar AVE masing-masing konstruk laten bel laten terdapat pada tabel berikut:

Tabel 3 Nilai Akar AVE

\begin{tabular}{lccc}
\hline \multicolumn{1}{c}{ Variabel } & Simbol & AVE & Akar Kuadrat AVE \\
\hline Employee outcome & EO & 0,520 & 0,721 \\
\hline Job satisfaction & JS & 0,532 & 0,729 \\
\hline Personality congruence & PC & 0,534 & 0,731 \\
\hline Values congruence & VC & 0,811 & 0,900 \\
\hline Work Environment Congruence & WEC & 0,685 & 0,828 \\
\hline
\end{tabular}

Sumber: data diolah, 2020 
Pradana, D.W. \& Tulasi, D. (2021). Pengaruh Person Organization Fit Terhadap Employee Outcomes Dengan Job ...

Tabel 4. Nilai Cronbach's Alpha dan Composite Reliability

\begin{tabular}{lcc}
\multicolumn{1}{c}{ Variabel } & Cronbach's Alpha & Composite Reliability \\
\hline Employee Outcome & 0,712 & 0,740 \\
\hline Job Satisfaction & 0,717 & 0,770 \\
\cline { 2 - 3 } Personality Congruence & 0,721 & 0,835 \\
\hline Values Congruence & 0,748 & 0,789 \\
\hline Work Environment Congruence & 0,823 & 0,893 \\
\hline
\end{tabular}

Sumber: data diolah, 2020

Hasil pengukuran pada Tabel 4 me-nunjuk- $\quad$ yaitu 0,6. Selain itu, nilai composite reliability lekan semua konstruk memiliki nilai Cronbach's bih besar dari pada kriteria kehandalan (cut-off alpha lebih besar dari pada kriteria kehandalan value) yakni 0,7 sehingga dinyatakan reliabel.

Tabel 5 Nilai R-Square

\begin{tabular}{lcc}
\hline \multicolumn{1}{c}{ Variabel } & $\boldsymbol{R}$ Square & $\boldsymbol{R}$ Square Adjusted \\
\hline Employee outcome & 0,762 & 0,752 \\
\hline Job satisfaction & 0,453 & 0,437 \\
\hline
\end{tabular}

Sumber: data diolah, 2020

Nilai $R$-Square adjusted konstruk employee ruences, values congruences, dan work environment outcome (EO) sebesar 0,752 menunjukkan bahwa congruence sebesar 43,7\%, sedangkan sisanya variasi konstruk employee outcome (EO) yang dipe- sebanyak 56,3\% dipengaruhi oleh variabel lain di ngaruhi oleh variable job satisfaction (JS), person- luar model penelitian. Inner model digunakan unality congruence $(P C)$, values congruence (VC), dan tuk menunjukkan hubungan kausal antar variabelwork environment congruence (WEC) sebesar variabel laten eksogen dan variabel laten endogen $75,20 \%$, sedangkan sisanya sebanyak $24,80 \%$ dipe- (structural model). Adapun model struktural yang ngaruhi oleh variabel lain di luar model penelitian. dikembangkan, mengacu pada nilai path coefficiBegitu pula konstruk job satisfaction yang memiliki ents, sebagaimana tertuang dalam tabel 6 . Tabel 6 nilai $R$-Square adjusted sebesar 0,437 menunjuk- menunjukkan nilai koefisien jalur (path coefficient) kan bahwa perubahan konstruk job satisfaction langsung dari masing-masing variabel independen yang dipengaruhi oleh variable personality cong- ke variabel dependen.

Tabel 6. Koefisien Jalur Pada Pengujian Model Struktural

\begin{tabular}{|c|c|c|c|c|c|}
\hline & $\begin{array}{c}\text { Original Sample } \\
\text { (0) }\end{array}$ & $\begin{array}{c}\text { Sample Mean } \\
\text { (M) }\end{array}$ & $\begin{array}{c}\text { Standard Deviation } \\
\text { (STDEV) }\end{array}$ & $\begin{array}{l}\text { T Statistics } \\
\text { (|0/STDEV|) }\end{array}$ & $\begin{array}{c}\mathbf{P} \\
\text { Values }\end{array}$ \\
\hline JS -> EO & 0,727 & 0,263 & 0,201 & 3,617 & 0,000 \\
\hline PC -> EO & 0,500 & 0,048 & 0,112 & 4,461 & 0,000 \\
\hline $\mathrm{PC}->\mathrm{JS}$ & 0,433 & 0,686 & 0,062 & 7,039 & 0,000 \\
\hline $\mathrm{VC}->\mathrm{EO}$ & 0,325 & 0,005 & 0,071 & 4,572 & 0,000 \\
\hline VC $->$ JS & 0,515 & 0,083 & 0,101 & 5,079 & 0,000 \\
\hline $\begin{array}{c}\text { WEC -> } \\
\text { EO }\end{array}$ & 0,348 & 0,002 & 0,054 & 6,387 & 0,000 \\
\hline WEC -> JS & 0,545 & 0,079 & 0,082 & 6,691 & 0,000 \\
\hline
\end{tabular}

Sumber: data diolah, 2020

Merujuk pada hasil penelitian empiris, di- pertama yang menyatakan, values congruence berketahui bahwa variabel values congruence ber- pengaruh positif dan signifikan terhadap empengaruh positif dan signifikan terhadap employee ployee outcome karyawan Perguruan Tinggi outcome. Hasil penelitian ini mendukung hipotesis Swasta di Surabaya. Hal ini berarti bahwa sema- 
kin besar kesesuaian antara nilai-nilai karyawan (values congruence) dengan nilai-nilai organisasi maka semakin meningkat pula employee outcome.

Hasil penelitian ini sejalan dengan penelitian Dunaetz et al., (2020) yakni values congruence memiliki pengaruh yang signifikan terhadap komitmen organisasional sebagai salah satu bentuk employee outcome. Temuan ini juga selaras dengan pernyataan Seggewiss et al., (2019) bahwa values congruence berkontribusi terhadap komitmen nilai yang berkaitan dengan ekspektasi kinerja karyawan.

Hal ini berarti seorang karyawan yakin nilai-nilai individualnya sesuai dengan nilai-nilai organisasi dan karyawan lain pada peru-sahaan, nilai-nilai dari organisasi merefleksikan nilai-nilai dan kepribadian sendiri, dan idealisme yang dicari dari sebuah organisasi, sudah terpenuhi bagi karyawan.

Hasil penelitian ini menunjukkan personality congruence berpengaruh positif dan signifikan terhadap employee outcome. Oleh karena itu hipotesis kedua yang menyatakan, personality congruence berpengaruh positif terhadap employee outcome karyawan pada Perguruan Tinggi Swasta di Surabaya didukung oleh bukti empiris dari penelitian ini.

Temuan ini mendukung hasil penelitian Perera, (2014) bahwa semakin besar employee organization congruence maka semakin besar pula employee outcome. Kristof, (1996) menemukan bahwa PO fit berdasarkan personality memiliki pengaruh yang kuat terhadap sikap-sikap dan perilaku-perilaku individual dari pada kecocokan berdasarkan nilai-nilai (values based fit). Lalu hasil penelitian Uysal-Irak (2017) menunjukkan "personality congruence was signifi-cantly correlated with employee satisfaction"

Hal ini berarti bahwa karyawan meyakini bahwa ada banyak kesamaan antara tujuan kolektif organisasi dengan tujuan pribadinya, ada tujuan yang ditetapkan untuk diri sejalan dengan tujuan organisasi, dan ada kepercayaan diri bahwa karyawan mampu mencapai tujuan organisasi.

Berdasarkan hasil analisis data diketahui bahwa work environment congruence berpengaruh positif dan signifikan terhadap employee outcome. Oleh karena itu hipotesis ketiga yang menyatakan work environment congruence berpengaruh positif dan signifikan terhadap employee outcome karyawan pada Perguruan Tinggi Swasta di Surabaya, didukung oleh hasil penelitian ini.

Hasil penelitian ini mendukung temuan Perera (2014) dan Naz et al., (2020). Perera (2014) menemukan bahwa semakin besar employyee organization congruence (values congruence, personality congruence, work environment congruence dan organizational vlaues) maka semakin besar pula employee outcome. Naz et al., (2020) menemukan bahwa adanya kesesuaian antara work environment congruence dengan nilai organisasi meningkatkan kepuasan kerja (job satisfaction) karyawan yang disebutnya sebagai salah satu employee commitment.

Artinya, terdapat persepsi positif dari para karyawan bahwa ada banyak orang dalam organisasi yang berbagi tentang hal-hal baik yang dilakukan saat bekerja, karyawan memiliki standar kualitas/etos kerja yang dibutuhkan untuk mencapai keberhasilan organisasi, dan teman-teman kerjanya mengapresiasi kualitas kerja yang berhubungan dengan tujuan organisasi. 
Pradana, D.W. \& Tulasi, D. (2021). Pengaruh Person Organization Fit Terhadap Employee Outcomes Dengan Job ...

Berdasarkan hasil analisis data diketahui bahwa terdapat pengaruh yang positif dan signifikan variabel kepuasan kerja terhadap employee outcome (organizational commitment). Dengan demikian hipotesis keempat yang menyatakan terdapat pengaruh variabel kepuasan kerja terhadap employee outcome, didukung oleh hasil penelitian ini. Hasil penelitian ini mendukung temuan terdahulu yang menyatakan job satisfaction dapat memprediksi organizational commitment (Valaei \& Rezaei, 2016).

Oleh karena itu dapat dinyatakan bahwa para karyawan memiliki persepsi, pekerjaannya menarik, perusahaan memberikan kesempatan untuk belajar, menerima tanggung jawab, dan maju dalam organisasi, penyelia/atasan dan rekan kerja memberikan dukungan demi penyelesaian pekerjaan.

Berdasarkan hasil penelitian diketahui bahwa variabel kepuasan kerja (job satisfaction) memediasi pengaruh values congruence terhadap employee outcome. Hal ini diketahui dari hasil analisis data yang menunjukkan variabel values congruence berpengaruh positif dan signifikan terhadap employee outcome (organizational commimtment) dan job satisfaction, lalu variabel job satisfaction berpengaruh positif dan signifikan terhadap employee outcome.

Maka hipotesis ke-lima yang menyatakan kepuasan kerja memediasi pengaruh values congruence terhadap employee outcome karyawan Perguruan Tinggi Swasta di Surabaya, didukung oleh hasil penelitian ini.

Temuan ini juga mendukung hasil penelitian Naz et al., (2020) tentang faktor yang memengaruhi $P O$ fit dan organization commitment dan selanjutnya terhadap employee retention yang dimediasi oleh employee outcome (organizational commitment).

Dengan demikian disimpulkan bahwa kepuasan kerja (job satisfaction) dapat memediasi pengaruh value congruence terhadap employee outcome yang pada penelitian ini diproksikan dengan organizational commitment. Artinya kesamaan nilai-nilai individual dan nilai-nilai organisasi akan memengaruhi employee outcome jika ada kepuasan kerja pada diri karyawan.

Hipotesis keenam menyatakan, kepuasan kerja memediasi pengaruh personality congruence terhadap employee outcome karyawan pada Perguruan Tinggi Swasta di Surabaya. Hasil penelitian ini menunjukkan bahwa variabel personality congruence memiliki pengaruh positif dan signifikan terhadap employee outcome dan kepuasan kerja (job satisfaction), lalu variabel kepuasan kerja juga berpengaruh positif dan signifikan terhadap employee outcome. Maka disimpulkan bahwa kepuasan kerja (job satisfaction) memediasi pengaruh personality congruence terhadap employee outcome karyawan Perguruan Tinggi Swasta di Surabaya. Artinya hipotesis kelima, didukung oleh hasil penelitian ini.

Hasil penelitian ini tidak sesuai dengan penelitian (Haerani et al., 2020) yang menyatakan bahwa PO fit tidak memengaruhi organizational commitment. Namun penelitian ini menegaskan kembali hasil penelitian Kristof (1996) yang menyatakan, kepuasan kerja (job satisfaction) memediasi hubungan antara $P O$ fit dan employee outcomes (organizational commitment). Dalam konteks ini, karyawan meyakini bahwa bila ada kesamaan antara tujuan pribadi dan tujuan orga- 
nisasi, lalu ada kepuasan kerja pada diri karyawan maka dapat meningkatkan employee outcome.

Hasil analisis menunjukkan bahwa kepuasan kerja memediasi pengaruh work environment congruence terhadap employee outcomes karyawan Perguruan Tinggi Swasta di Surabaya. Hal ini dibuktikan dari dengan pengaruh positif dan signifikan variabel work environment congruence terhadap employee outcomes (organizational commitment) dan kepuasan kerja (job satisfaction), serta pengaruh yang positif dan signifikan variabel kepuasan kerja (job satisfaction) terhadap employee outcomes (organizational commitment). Maka hipotesis ke-tujuh dapat dibuktikan oleh hasil penelitian ini.

Hasil penelitian ini mendukung penelitian Naz et al., (2020) tentang factor supportive work environment congruence terhadap variabel kepuasan kerja, lalu terhadap employee outcome (organizational commitment). Dengan demikian disimpulkan, para karyawan memiliki persepsi bahwa lingkungan kerja mendukung keberhasilan kerjanya sehingga puas atas pekerjaannya dan selanjutnya memengaruhi employee outcome.

Bentuk dukungan lingkungan kerja ini dapat dilihat pada banyak orang (atasan, rekan kerja) dalam organisasi yang dapat berbagi tentang hal-hal baik, rekan kerja yang mengapresiasi kualitas kerjanya yang berhubungan dengan tujuan organisasi.

\section{SIMPULAN}

Berdasarkan hasil analisis dan pembahasan tentang hubungan antara faktor person-organization fit dan employee outcomes yang pada penelitian ini diproksikan dengan komitmen organisasional (organizational commitment), diper- oleh simpulan sebagai berikut: (1) values congruence berpengaruh positif dan signifikan terhadap employee outcome; (2) personality congruence berpengaruh positif dan signifikan terhadap employee outcome; (3) work environment congruence berpengaruh positif dan signifikan terhadap employee outcome; (4) kepuasan kerja berpengaruh positif dan signifikan terhadap employee outcome; (5) kepuasan kerja (job satisfaction) memediasi pengaruh values congruence terhadap employee outcome; (6) kepuasan kerja memediasi pengaruh personality congruence terhadap employee outcome; (7) kepuasan kerja memediasi pengaruh work environment congruence terhadap komitmen organisasional.

Maka kesimpulan integratif dari penelitian ini adalah person organization fit dapat mempengaruhi employee outcome baik secara langsung maupun melalui job satisfaction sebagai variabel intervening.

\section{DAFTAR PUSTAKA}

Allen, N. J., \& Meyer, J. P. (1990). The measurement and antecedents of affective, continuance and normative commitment to the organization Journal of Occupational Psychology, 63(1), 1-18.

Arkoubi, K.A., Bishop, J. W., \& Scott, D. (2011). An investigation of the determinants of turnover intention among drivers". Loyola University, Chicago, 5(2), 470-480.

Astakhova, M. N. (2016). Explaining the effects of perceived person-supervisor fit and personorganization fit on organizational commitment in the U.S. and Japan. Journal of Business Research, 69(2), 956-963. https://doi.org/https://doi.org/10.1016/j.jbusre s.2015.08.039

Chen, P., Sparrow, P., \& Cooper, C. (2016). The relationship between person-organization fit and job satisfaction. Journal of Managerial Psychology.

Ćulibrk, J., Delić, M., Mitrović, S., \& Ćulibrk, D. (2018). Job satisfaction, organizational commitment and job involvement: The mediating role of job involvement. Frontiers in Psychology, 9, 132.

Dunaetz, D., Smyly, C., Fairley, C., \& Heykoop, C. (2020). Values congruence and organizational 
Pradana, D.W. \& Tulasi, D. (2021). Pengaruh Person Organization Fit Terhadap Employee Outcomes Dengan Job ...

commitment in churches: When do shared values matter? Psychology of Religion and Spirituality. https://doi.org/10.1037/rel0000314

Haerani, S., Sumardi, Sumardi Hakim, W., \& Hartini, Hartini Putra, A. H. P. K. (2020). Structural model of developing human resources performance: Empirical study of Indonesia states owned enterprises. The Journal of Asian Finance, Economics, and Business, 7(3), 211-221.

Hair, J. F., Hult, G. T. M., Ringle, C., \& Sarstedt, M. (2016). A Primer on Partial Least Squares Structural Equation Modeling (PLS-SEM). SAGE Publications. https://books.google.co.id/books?id=JDWmCwA AQBAJ

Kristof, A. L. (1996). Person-organization fit: An integrative review of its conceptualizations, measurement, and implications. Personnel Psychology, 49(1), 1-49.

Lau, P. Y. Y., McLean, G. N., Hsu, Y.-C., \& Lien, B. Y.-H. (2017). Learning organization, organizational culture, and affective commitment in Malaysia: A person--organization fit theory. Human Resource Development International, 20(2), 159-179.

Luthans, F. (2015). Organizational Behavior (13th ed.). The McGrow-Hill Companies, Inc.

Magdalena, S. M. (2014). The effects of organizational citizenship behavior in the academic environment. Procedia-Social and Behavioral Sciences, 127, 738-742.

Nasution, M. I. (2017). Pengaruh stres kerja, kepuasan kerja dan komitmen organisasi terhadap turnover intention medical representative. MIX: Jurnal Ilmiah Manajemen, 7(3).

Naz, S., Li, C., Nisar, Q. A., Khan, M. A. S., Ahmad, N., \& Anwar, F. (2020). A study in the relationship between supportive work environment and employee retention: role of organizational commitment and person-organization fit as mediators. SAGE Open, 10(2), 2158244020924694.

https://doi.org/10.1177/2158244020924694

Perera, G. D. N. (2014). impact of employeeorganization congruence on job satisfaction and job performance among factory employees in the sri lankan large apparel sector. Proceedings of the HR Conference, 01(01)

Rumangkit, S., \& Maryati, S. (2017). Pengaruh personorganization fit terhadap komitmen organisasional melalui kepuasaan kerja pada karyawan ibi darmajaya. Optimum: Jurnal Ekonomi Dan Pembangunan, 7, 190. https://doi.org/10.12928/optimum.v7i2.7918

Seggewiss, B. J., Boeggemann, L. M., Straatmann, T., Mueller, K., \& Hattrup, K. (2019). Do values and value congruence both predict commitment? a refined multi-target, multi-value investigation into a challenged belief. Journal of Business and Psychology, 34(2), 169-187. https://doi.org/10.1007/s10869-018-9534-0

The Society for Human Resources Management (SHRM). (2020). No Title. https://www.shrm.org/

Uysal-Irak, D. (2017). Personal-Organizational Value Congruence as a Mediator Between Personality and Employee Attitudes. https://doi.org/10.5772/intechopen.68239

Valaei, N., \& Rezaei, S. (2016). Job satisfaction and organizational commitment: An empirical investigation among ICT-SMEs. Management Research Review. 